\title{
Simples Nacional: vantagens e desvantagens entre o lucro presumido e o lucro real
}

\author{
Paulo Cruz Correia - correiapc@ yahoo.com.br \\ UNESPAR - Universidade Estadual do Paraná \\ Benedito Alberto da Silva - bene_@alberto@hotmail.com \\ UNESPAR - Universidade Estadual do Paraná \\ Noelia Felipe - noeliafelipe@uol.com.br \\ UNESPAR - Universidade Estadual do Paraná \\ Antonio Manoel Conceição - proftoni@uol.com.br \\ UNESPAR - Universidade Estadual do Paraná \\ Leonardo Fávero Sartori - lfsartori@gmail.com \\ UNESPAR - Universidade Estadual do Paraná
}

\section{Resumo}

A arrecadação de imposto no Brasil acontece desde o período colonial no século $\mathrm{XV}$, quando os portugueses exploraram o solo brasileiro, e é esta prática que sustenta os gastos do governo até hoje. Os tributos são necessários para custear as despesas públicas da União, Estados, Distrito Federal e dos Municípios. Com a retração econômica e dos investimentos empresariais, novas modalidades de tributos estão sendo lançados pelo governo. Este artigo busca analisar o impacto do ICMS - pago pelas empresas optantes pelo Simples Nacional, e uma comparação de tributação nas empresas tributadas pelo Lucro Presumido e o Lucro Real, vantagens e desvantagens para as micro e pequenas empresas, quando estas operam produtos enquadrados em Substituição Tributária. A metodologia utilizada é a da pesquisa bibliográfica, artigos, livros, revista e sites e pesquisa documental; e, observação em escritório da área contábil.

Palavras chave: Substituição Tributária, Imposto, Simples Nacional

\section{Abstract}

The tax collection in Brazil comes from the colonial period in the fifteenth century, when the Portuguese explored the Brazilian soil, and it is this practice that supports government spending to date. Taxes are needed to fund public expenditure of the Union, States, Federal District and Municipalities. With the economic downturn and business investment, new forms of taxes are being launched by the government. This article seeks to analyze the impact of ICMS - paid by companies opting for Simples Nacional, and a tax comparison in companies taxed by presumed income and taxable income, advantages and dis advantages for micro and small enterprises when they operate products framed in Replacement tax. The methodology used is that of literature, articles, books, magazines and websites and documentary research; and, observatory in the accounting area office.

Key words: Tax substitution, Tax, National Simple 


\section{INTRODUÇÃO}

Os tributos incidem sobre comercialização, industrialização, e prestação de serviços, de transportes estaduais e interestaduais. É neste sentido que este artigo busca analisar o impacto do ICMS, em especial das empresas optantes do Simples Nacional, o ICMS-S.T(Substituição Tributária), direcionado às MPEs (Micro e Pequenas Empresas); e, verificar se, nesse caso está recebendo o tratamento tributário diferenciado, previsto naLei Complementar 123/2006.

Em relação ao foco teórico, consideram-se aspectos tributários discutidos em REZENDE (2010); WANKE e MAGALHÃES (2012) a opção do Simples Nacional está relacionada a uma série de condições como: a) Ramo de atividade econômica exercida - empresas que atuam como instituições financeiras e câmbio não podem enquadrar-se neste regime; b) $\mathrm{O}$ capital social - em sociedades que o sócio reside no estrangeiro ou outra pessoa jurídica, não podem optar; c) Tipos de organizações - sociedades de ações, não são permitidas.

Em relação ao foco metodológico, o estudo envolve a observação em escritório contábil, uma breve revisão da lei 123/2006, autores da área contábil como: FABRETTI (2008), SOUZA (2008) e (WANKE e MAGALHÃES 2012). A pesquisa foi realizada para responder à indagação principal, ou seja, quanto às vantagens e desvantagens do Simples Nacional, tomou como exemplo uma empresa com faturamento médio de $\mathrm{R} \$ 100.000,00$ como parâmetro fictício, valor que corresponde a um grande número de empresas que atuam no mercado, com intuito de aproximar do mundo real, descrevendo como as situações se comportam.

A pesquisa está organizada em cinco seções, além desta introdução, a seção dois apresenta os resultados e discussão, cálculo do ICMS-S.T para empresas optantes ao Simples Nacional; e, os reflexos do ICMS sobre a receita e custos operacionais nas MPEs optantes; reflexos do ICMS sobre o lucro nas empresas optantes ao Simples Nacional. A terceira envolve a diferença entre o preço de venda e custo realizados pelas empresas optantes, envolvendo operações com ICMS-ST e tributação integral, a quarta discute as vantagens da opção pelo Simples Nacional; o Lucro Presumido. Na quinta seção, observa-se a base de cálculo para PIS e COFINS; a base de cálculo da Contribuição Social Sobre o Lucro Líquido (CSLL) e o Lucro Real. E, por último, as considerações finais.

\section{ANÁLISE DOS RESULTADOS}

\subsection{Cálculo do ICMS-S.T Para Empresas Optantes ao Simples Nacional}

Adquirindo um produto com substituição tributária a Micro empresa, irá pagar o mesmo valor que uma empresa normal, neste caso, não há tratamento diferenciado. Para o governo a criação de substitutos tributários é muito forte, face à enorme facilidade de apuração devido à redução de sonegação fiscal. Conforme o quadro 1 (ASSEF, 2003).

Quadro 1-ICMS-S.T para empresas optantes ao Simples Nacional:

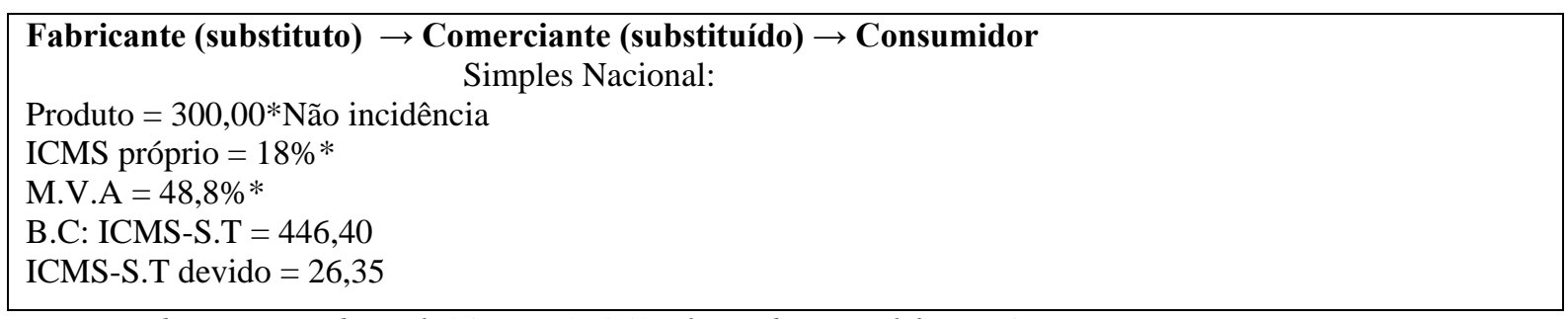

Fonte: Dados organizados pelo(s) autor(es) (*valores de exemplificação).

O valor do ICMS-S.T é de R \$26,35, um custo a mais na comercialização do produto, Assim, conclui-se que as empresas optantes, ao receber produtos com incidência da Substituição Tributária não recebe os benefícios da Lei Complementar 123 de 2006. 


\subsubsection{Reflexos do ICMS Sobre a Receita e Custos nas empresas Optantes ao Simples Nacional}

Os reflexos do ICMS-S.T nas empresas optantes serão demonstrados através de cálculos, considerando o preço de venda no Estado do Paraná e a mesma margem de lucro, utilizando o Markup, sintetizado por COGAN (2002). Para exemplificar, uma indústria que emite uma nota fiscal para outro Estado, os seguintes dados, do quadro número 2:

Quadro 2- Considerando a Nota Fiscal de venda número 10*:

\begin{tabular}{|c|c|c|c|}
\hline Base de cálculo & ICMS $12 \% *$ & Total da NF $\mathrm{n}^{\mathbf{0}} 10$ \\
$\mathrm{R} \$ 300,00^{*}$ & $\mathrm{R} \$ 36,00$ & $\mathrm{R} \$ 30,00$ & $\mathrm{R} \$ 330,00$ \\
\hline
\end{tabular}

Fonte: Dados organizados pelo(s) autor(es) (*valores de exemplificação).

Aplicando 12\%* de ICMS e o IPI de 10\%* obtém-se conforme o quadro acima. Neste exemplo, a alíquota do Estado vendedor é de $12 \% *$ e do comprador é de $18 \% *$, há um percentual de $6 \%$ (diferença entre 12\%* e 18\%*). Diante das informações calculamos o custo e o preço de venda, conforme o quadro 3 e gráfico 1 .

Quadro 3- Considerando a formação do custo tributado integral na microempresa:

\begin{tabular}{|l|c|}
\hline Valor do produto & $\mathrm{R} \$ 300,00$ \\
\hline Valor do IPI & $\mathrm{R} \$ 30,00$ \\
\hline Valor do ICMS sobre o diferencial de alíquota & $\mathrm{R} \$ 18,00$ \\
\hline Custo total & $\mathbf{R} \mathbf{3 4 8 , 0 0}$ \\
\hline
\end{tabular}

Fonte: Dados organizados pelo(s) autor(es).

Na venda utilizou-se a tabela abaixo do Simples Nacional pela alíquota de 2,33\% de ICMS, pois a empresa compreende a um faturamento médio anual entre $\mathrm{R} \$ 360.000,01$ a $\mathrm{R} \$ 540.000,00$; não incorporados PIS, COFINS, IRPJ, CSLL e CPP, observados no quadro 4.

Quadro 4- Considerando a Receita Bruta da empresa nos últimos 12 meses:

\begin{tabular}{|l|c|c|c|c|l|l|l|}
\hline $\begin{array}{l}\text { Receita Bruta em 12 meses (em } \\
\text { R\$) }\end{array}$ & Alíquota & IRPJ & CSLL & COFINS & PIS & CPP & ICMS \\
\hline Até 180.000,00 & $4,00 \%$ & $0,00 \%$ & $0,00 \%$ & $0,00 \%$ & $0,00 \%$ & $2,75 \%$ & $1,25 \%$ \\
\hline De 180.000,01 a 360.000,00 & $5,47 \%$ & $0,00 \%$ & $0,00 \%$ & $0,86 \%$ & $0,00 \%$ & $2,75 \%$ & $1,86 \%$ \\
\hline De 360.000,01 a 540.000,00 & $6,84 \%$ & $0,27 \%$ & $0,31 \%$ & $0,95 \%$ & $0,23 \%$ & $2,75 \%$ & $\mathbf{2 , 3 3 \%}$ \\
\hline De 540.000,01 a 720.000,00 & $7,54 \%$ & $0,35 \%$ & $0,35 \%$ & $1,04 \%$ & $0,25 \%$ & $2,99 \%$ & $2,56 \%$ \\
\hline De 720.000,01 a 900.000,00 & $7,60 \%$ & $0,35 \%$ & $0,35 \%$ & $1,05 \%$ & $0,25 \%$ & $3,02 \%$ & $2,58 \%$ \\
\hline De 900.000,01 a 1.080.000,00 & $8,28 \%$ & $0,38 \%$ & $0,38 \%$ & $1,15 \%$ & $0,27 \%$ & $3,28 \%$ & $2,82 \%$ \\
\hline DE 1.080.000,01 a 1.260.000,00 & $8,36 \%$ & $0,39 \%$ & $0,39 \%$ & $1,16 \%$ & $0,28 \%$ & $3,30 \%$ & $2,84 \%$ \\
\hline
\end{tabular}

Fonte: Simples Nacional (2016) adaptada.

Então temos, conforme apresentado no quadro número 5.

Quadro 5- Preço de venda à empresa de preferência integral ao Simples Nacional:

\begin{tabular}{|l|c|}
\hline Custo da compra & $\mathrm{R} \$ 348,00^{*}$ \\
\hline ICMS (simples nacional) & $2,33 \%$ \\
\hline Índice divisor para venda & 0,6767 \\
\hline
\end{tabular}




\begin{tabular}{|c|r|}
\hline Preço de venda & $\mathbf{5 1 4 , 2 6}$ \\
\hline Fonte: Dados organizados pelo(s) autor(es) (*valores de exemplificação).
\end{tabular}

A venda foi formada com os valores a seguir, para encontrar o índice de divisor para venda foi considerado a alíquota integral do Simples Nacional, menos o ICMS da tabela do Anexo I da Lei 123 de 2006, mais o percentual de redução de ICMS, conforme quadro 12.

*Memória de cálculo do índice: $6,84 \%-(2,33 \%-0,67 \%)=5,18 \%$;

$5,18 \%+30 \%=35,18 \% \rightarrow(100 \%-35,18 \%)=(64,82 / 100)=0,6767 \rightarrow 348,00 / 0,6767=$ 514,26; temos um custo de produto de $\mathrm{R} \$ 348,00$;

ICMS (alíquota do Simples): 514,26 x $(2,33 \%-0,67)=1,66 \% \rightarrow \mathrm{R} \$ 8,54$

Memória de cálculo 514,26 - $(348,00+8,54)=157,72$; e, Lucro da venda: R\$157,72.

Com base acima, o lucro da empresa foi de 157,72. Nas empresas de categoria geral o custo é formado com o valor do produto, mais o IPI, descontados o ICMS próprio e ICMS de diferencial de alíquota. Estes valores são descontam dos custos da empresa, pois esta categoria permite o aproveitamento de crédito de ICMS, estabelecido pela legislação, de acordo com o quadro 6.

Quadro 6- O custo em empresas de categoria geral com tributação integral de ICMS:

\begin{tabular}{|l|c|}
\hline Custo da compra & $\mathrm{R} \$ 300,00^{*}$ \\
\hline IPI $(10 \%)$ & $\mathrm{R} \$ 30,00^{*}$ \\
\hline ICMS sobre o diferencial de alíquota $(6 \%)^{*}$ & $(18,00)^{*}$ \\
\hline ICMS próprio $(12 \%)^{*}$ & $(36,00)^{*}$ \\
\hline Custo total & $\mathbf{R} \mathbf{2 7 6 , 0 0}$ \\
\hline
\end{tabular}

Fonte: Dados organizados pelo(s) autor(es) (*valores de exemplificação).

Em vendas será necessário considerar a margem de 30\%* e o ICMS de 18\%*.

Quadro 7- Preço de vendas em empresas de categoria normal e tributação integral de ICMS:

\begin{tabular}{|l|c|}
\hline Custo da compra & $\mathrm{R} \$ 276,00$ \\
\hline ICMS próprio & $18 \% *$ \\
\hline Margem de lucro & $30 \% *$ \\
\hline Índice divisor para venda & 0,52 \\
\hline Preço de venda & $\mathbf{R} \$ \mathbf{5 3 0 , 7 7}$ \\
\hline
\end{tabular}

Fonte: Dados organizados pelo(s) autor(es) (*valores de exemplificação).

Para encontrar o índice de divisor para venda foi considerado o valor do custo, dividido pelo percentual de ICMS próprio de $18 \%$, mais a margem de lucro de $30 \%$, então temos, apresentado no quadro 7:

*Memória de cálculo do índice: $(18 \% *+30 \% *)=48 \% ;(48 / 100)=0,48 \rightarrow(1-0,48)=0,52$; $276,00 / 0,52=530,77 ;$ logo temos os Custos dos produtos = R $\$ 276,00 ;$ ICMS: $530,77 \times 18 \%=\mathrm{R} \$$ 95,54; Memória de cálculo: 530,77 - (276,00+95,54) = 159,23; Lucro da venda: R\$ 159,23.

A empresa optante realizou venda no valor de $\mathrm{R} \$ 514,26$, obteve um lucro de 157,72 . A empresa de categoria normal, ao vender no valor de $\mathrm{R} \$ 530,77$, alcançou um lucro de 159,23 . Ao verificar os valores dos custos e o das vendas atingidas pelas duas empresas, então o custo é maior na empresa optante ao Simples Nacional, considerando a mesma margem de lucro.

\subsubsection{Reflexos do ICMS S.T sobre a margem de lucro nas Optantes ao Simples Nacional}

Em relação ao impacto do ICMS-S.T nas empresas tributadas pelo Simples Nacional sobre o lucro sobre vendas, tem-se conforme o quadro 8. 
Quadro 8-O exemplo da Nota Fiscal de venda $n^{\circ} 11^{*}$

\begin{tabular}{|l|l|l|l|l|c|}
\hline Base de cálculo: & ICMS: & IPI: & ICMS-S.T: & $\begin{array}{l}\text { Total } \\
\text { produtos: }\end{array}$ & $\begin{array}{l}\text { Total da Nota } \\
\text { Fiscal: }\end{array}$ \\
\hline $\mathrm{R} \$ 300,00^{*}$ & $\begin{array}{c}12 \% * \\
\mathrm{R} \$ 36,00\end{array}$ & $\begin{array}{c}10 \% * \\
\mathrm{R} \$ 30,00\end{array}$ & $50 \% * \mathrm{R} \$ 89,10$ & $\mathrm{R} \$ 330,00$ & $\mathrm{R} \$ 419,10$ \\
\hline
\end{tabular}

Fonte: Dados organizados pelo(s) autor(es) (*valores de exemplificação).

Quadro 9- Exemplo da situação da Margem de valor agregado (M.V.A.):

\begin{tabular}{|l|c|c|c|}
\hline Tipos de Alíquota & \multicolumn{3}{|c|}{ Alíquota interna na unidade federativa de destino } \\
\hline Alíquota interestadual de 4\%* & $8 \% *$ & $12 \% *$ & $18 \%^{*}$ \\
\hline M.V.A. ajustado em \%* & $50 \%^{*}$ & $50 \% *$ & $61 \%^{*}$ \\
\hline
\end{tabular}

Fonte: Dados organizados pelo(s) autor(es) (*valores de exemplificação).

Utilizou-se uma margem de valor agregado, conforme o quadro 9, (M.V.A) de 50\%*, alíquota de ICMS próprio de 12\%*, IPI de 10\%* e ICMS-S.T de 18\%*; Valor dos produtos $=$ R $\$ 300,00 *$; Valor do IPI $=\mathrm{R} \$ 30,00$; ICMS próprio $=\mathrm{R} \$ 36,00^{*}$; Base de cálculo ICMS-S.T= $(300,00+30,00+50 \% *) \rightarrow \mathrm{R} \$ 495,00 *$; ICMS-ST $=(495,00 * 18 \% *)=\mathrm{R} \$ 89,10 *$; Total da Nota fiscal $=\mathrm{R} \$ 419,10$. Conforme o quadro 10 .

Quadro 10- Formação de custo com mercadoria em Substituição Tributária nas empresas do Simples Nacional:

\begin{tabular}{|l|c|}
\hline Custo da compra & R\$ 300,00* \\
\hline IPI $(10 \%)$ & $\mathrm{R} \$ 30,00^{*}$ \\
\hline ICMS-S.T & $\mathrm{R} \$ 89,10$ \\
\hline Custo total & $\mathbf{R} \mathbf{4 1 9 , 1 0}$ \\
\hline
\end{tabular}

Fonte: Dados organizados pelo(s) autor(es) (*valores de exemplificação).

O custo composto pelo valor da compra, ICMS-S.T e IPI. Tanto as empresas optantes e as empresas de categoria geral não têm o direito de aproveitar créditos de ICMS-ST, pois o valor do imposto foi recolhido na fonte ou origem, conforme o quadro 11, gráfico 2.

Para que ambas empresas obtenham a mesma lucratividade de $30 \% *$, o preço de venda será demonstrado no quadro abaixo. Verifica-se que, com base no valor da venda temos: 598,71 (-) o custo da compra: 419,10, o que resultou em um lucro apurado de $\mathrm{R} \$ 179,61$.

Quadro 11- Preço das vendas em Substituição Tributária nas empresas de Categoria Geral e Simples Nacional:

\begin{tabular}{|c|c|}
\hline Custo da compra & $\mathbf{R} \$ 419,10 *$ \\
\hline Margem de lucro & $30 \% *$ \\
\hline Índice de divisor para venda & 0,70 \\
\hline Valor da venda & R\$ 598,71 \\
\hline
\end{tabular}

Fonte: Dados organizados pelo(s) autor(es) (*valores de exemplificação). 


\subsubsection{Diferença entre o preço de venda e custos realizados pelas empresas optantes nas mercadorias adquiridas com ICMS-ST e ICMS de tributação integral}

Para realizar a comparação serão analisados os valores citados acima; nos quadros 12 e 13 das empresas em tributação, pelo Simples Nacional; serão simuladas compras e vendas de produto com substituição tributária e com tributação integral.

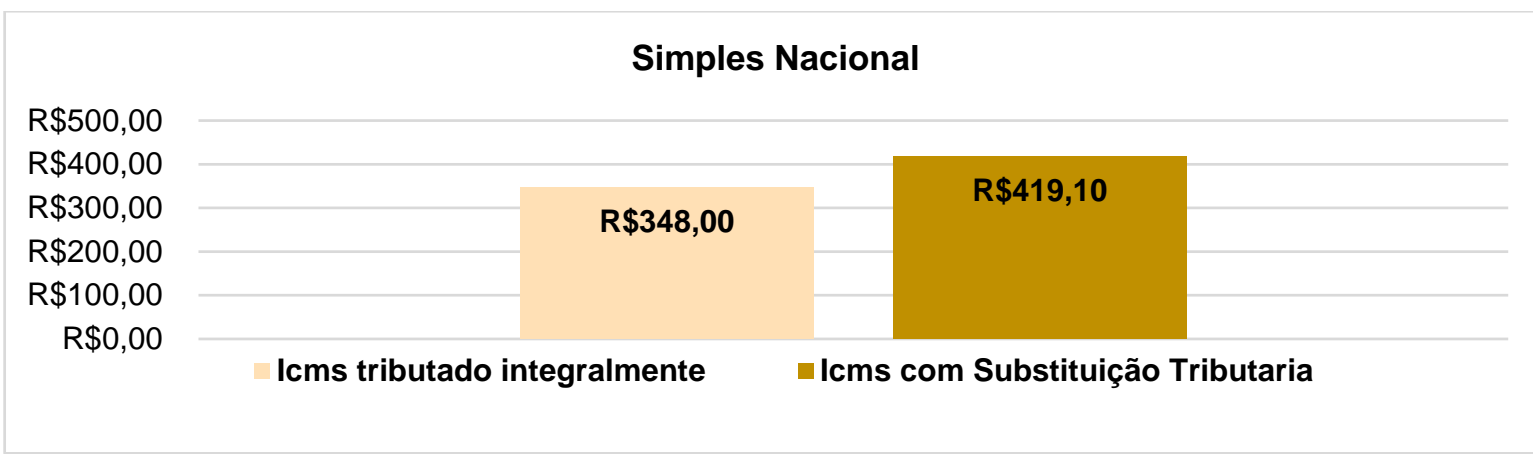

Gráfico 1- Formação dos custos - ICMS-S.T e ICMS Integral. Fonte: Dados organizados pelo(s) autor(es).

Acima, pode-se visualizar que adquirindo produtos com incidência de ICMS-S.T, o custo aumenta mais de $20 \%$ em relação ao mesmo produto sem incidência.

E na venda o ICMS-S.T foi de R \$ 89,10, o mesmo ocorre na empresa de categoria geral. Se a empresa do Simples resolvesse vender o mesmo produto, o valor pago do ICMS seria de R $\mathbf{8 , 5 4}$. Verifica-se a diferença ocorrida na tributação para a empresa optante em tributar integralmente e a substituição tributária.

Se a empresa adquirir produtos com ICMS-S.T e vender por R $\mathbf{5 1 4 , 2 6}$, sua margem de lucro seria de $18,5 \%$ e na aquisição da mercadoria tributada seria de $30 \%$. Portanto está prática contraria o art. 179 da C.F.As empresas optantes ao Simples Nacional têm o tratamento diferenciado no recolhimento de seus impostos, mas diante dessa situação de substituição tributária acaba sendo desfavorecida (LEI COMPLEMENTAR, 2006).

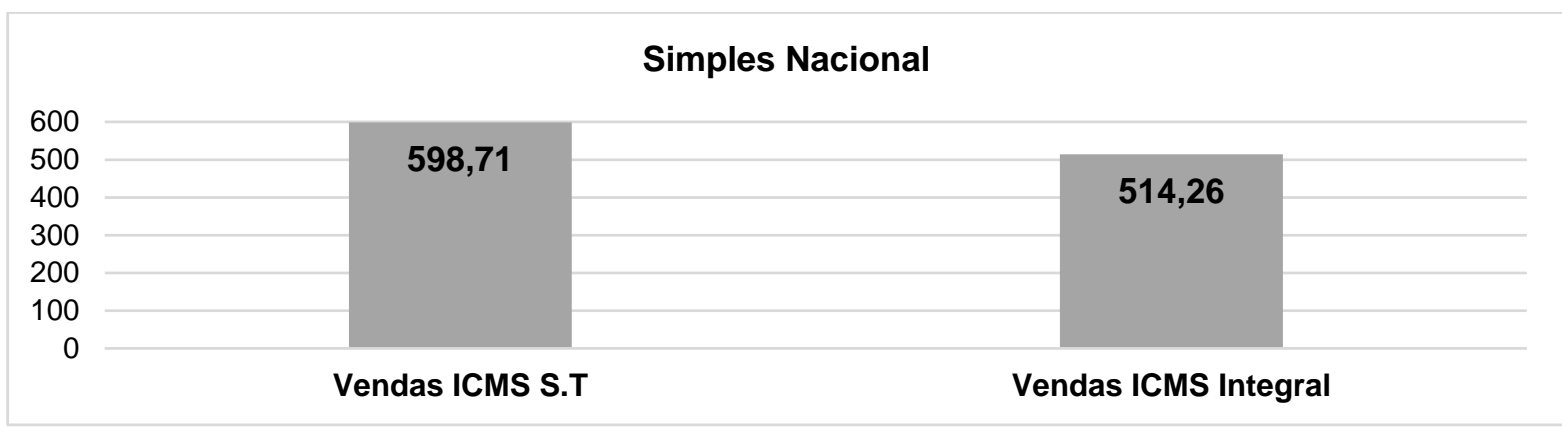

Gráfico 2 -Valor das vendas - ICMS-S.T e ICMS Integral. Fonte: Dados organizados pelo(s) autor(es).

Dessa forma a substituição tributária pode ferir os princípios, constitucional, da isonomia, da reserva legal, que atribuiu à lei complementar 123 de 2006 estabelecer regras de tributação das pequenas empresas; o princípio da segurança jurídica, o princípio da pequena empresa na ordem econômica nacional; e, todos aqueles que com eles se relacionam, especialmente os princípios sociais (MELCHOR, 2008). 


\subsubsection{As Vantagens da Opção Pelo Simples Nacional}

O Simples Nacional é um regime unificado e simplificado de recolhimento de tributos para as ME e EPP. Esse regime de tributação abrange todos os impostos dos entes federados (União, Estado, Distrito Federal e Municípios). Com a Lei das Micro e Pequenas Empresas muitas empresas saíram da informalidade, trazendo reflexos positivos nos aspectos tributários, na competitividade e no mercado de trabalho (WANKE e MAGALHÃES 2012).

Para SOUZA (2008), os benefícios são: i) Tributação com alíquotas mais favorecidas e progressivas, de acordo com a receita bruta auferida; ii) Recolhimento unificado de impostos e contribuições federais com a utilização de um único documento (DAS) que estão incluídos os impostos municipais, estaduais e federais; iii) Cálculo simplificado do valor a ser recolhido, apurado com base na aplicação de alíquotas unificadas e progressivas, fixadas em Lei, incidentes em uma base, a receita bruta mensal; v) Parcelamento de débitos de forma reduzidas.

No exemplo abaixo, considera-se uma empresa comercial que iniciou suas atividades no ano da opção pelo Simples e apresentou receita de $\mathrm{R} \$ 100.000,00$ no período. Para determinar a alíquota do Simples deverá multiplicar por doze meses a receita bruta para o cálculo (Simples Nacional 2015). Aplicando o percentual conforme o quadro 5, considerando um faturamento base de 100.000,00 x 12 meses $=\mathrm{R} \$ 1.200 .000,00$. Considerando, 100.000,00 x 12 meses $=\mathrm{R} \$ 1.200 .000,00$; Verifica-se então que a alíquota será de $8,36-2,84+1,83=7,35 \%$.

Quadro 12- Impostos na empresa enquadrada no Simples Nacional, em atividade de comércio:

\begin{tabular}{|l|l|l|l|l|l|l|}
\hline Impostos & IRPJ & CSLL & PIS & COFINS & INSS/CPP & ICMS \\
\hline Valor & $0,39 \%$ & $0,39 \%$ & $0,28 \%$ & $1,16 \%$ & $3,30 \%$ & $1,83 \%$ \\
\hline $\mathbf{1 0 0 . 0 0 0 , 0 0}$ & 390,00 & 390,00 & 280,00 & $1.160,00$ & $3.300,00$ & $1.830,00$ \\
\hline
\end{tabular}

Fonte: Dados organizados pelo(s) autor(es).

Quadro 13- O ICMS no Paraná, Microempresas e Empresas de Pequeno Porte optantes do Simples Nacional:

\begin{tabular}{|l|c|c|c|}
\hline Receita Bruta em 12 meses (em R\$) & $\begin{array}{c}\text { Percentual de } \\
\text { ICMS na LC } \\
\mathbf{n}^{\mathbf{0}} \mathbf{1 2 3 / 2 0 0 6}\end{array}$ & $\begin{array}{c}\text { Percentual de ICMS } \\
\text { observado pelas empresas } \\
\text { optantes do Simples Nacional } \\
\text { no Paraná }\end{array}$ & $\begin{array}{c}\text { Percentual de } \\
\text { redução a ser } \\
\text { informado no } \\
\text { PGDAS }\end{array}$ \\
\hline Até $180.000,00$ & $1,25 \%$ & Isenção & Informar isenção \\
\hline De 180.000,01 a 360.000,00 & $1,86 \%$ & Isenção & Informar isenção \\
\hline De 360.000,01 a 540.000,00 & $2,33 \%$ & $0,67 \%$ & $71,24 \%$ \\
\hline De 540.000,01 a 720.000,00 & $2,56 \%$ & $1,07 \%$ & $58,20 \%$ \\
\hline De 720.000,01 a 900.000,00 & $2,58 \%$ & $1,33 \%$ & $48,45 \%$ \\
\hline De 900.000,01 a 1.080.000,00 & $2,82 \%$ & $1,52 \%$ & $46,10 \%$ \\
\hline De 1.080.000,00 a 1.260.000,00 & $2,84 \%$ & $1,83 \%$ & $35,56 \%$ \\
\hline
\end{tabular}

Fonte: SEFA, (2016).

Aplicando a alíquota de 7,35\% temos, no quadro 12: 390,00 de IRPJ; 390,00 de CSLL; 390,00 de PIS; 1.160 de COFINS; 3.300,00 de INSS/CPP; e, 1.830,00 de ICMS, totalizando R\$ $7.350,00$ de Impostos. Para maior detalhamento, segue a demonstração no quadro abaixo. 
Quadro 14- Demonstração do Resultado na empresa optante do Simples Nacional - na atividade de comércio:

\begin{tabular}{|c|c|c|}
\hline DISCRIMINAÇÃO & $(-)$ & $(+)$ \\
\hline Receita de Vendas & & R\$ 100.000,00* \\
\hline (-) Impostos Sobre vendas & & $(\mathrm{R} \$ 3.270,00)$ \\
\hline ICMS sobre faturamento $-1,83 \%$ & $\mathrm{R} \$ 1.830,00$ & \\
\hline PIS sobre faturamento $-0,28 \%$ & $\mathrm{R} \$ 280,00$ & \\
\hline COFINS sobre faturamento $-1,16 \%$ & R\$ 1.160,00 & \\
\hline (=) Receita Líquida & & $\mathrm{R} \$ \mathbf{9 6 . 7 3 0 , 0 0}$ \\
\hline (-) Custos das mercadorias & & $(\mathbf{R} \$ 27.000,00)^{*}$ \\
\hline Compras de mercadorias & $\mathrm{R} \$ 27.000,00^{*}$ & \\
\hline (=) Lucro Bruto & & $\mathrm{R} \$ \mathbf{6 9 . 7 3 0 , 0 0}$ \\
\hline (-) Despesas Operacionais & & $(\mathrm{R} \$$ 6.000,00)* \\
\hline Despesas Administrativas & $\mathrm{R} \$ 3000,00 *$ & \\
\hline Despesas Financeiras & $\mathrm{R} \$ 3.000,00^{*}$ & \\
\hline (=) Lucro antes do IRPJ & & $\mathrm{R} \$ \mathbf{6 3 . 7 3 0 , 0 0}$ \\
\hline IRPJ $-0,39 \%$ & $\mathrm{R} \$ 390,00$ & \\
\hline CSLL $-0,39 \%$ & $\mathrm{R} \$ 390,00$ & \\
\hline INSS/CPP $-3,30 \%$ & $\mathrm{R} \$ 3.300,00$ & R\$ 4.080,00 \\
\hline (=) Lucro líquido do exercício & & R\$ 59.650,00 \\
\hline
\end{tabular}

Fonte: Dados organizados pelo(s) autor(es) (*valores de exemplificação).

-Não foi considerada a folha de pagamento dos empregados.

\subsubsection{O Lucro Presumido}

É uma forma de apuração com base na presunção do lucro, observando a atividade da empresa. FABRETTI (2008), afirma que o lucro presumido é um conceito tributário e tem a finalidade de facilitar o pagamento do IR, sem ter que recorrer à complexa apuração do lucro real. Em SANTOS (2008), o Lucro Presumido é uma forma de tributação simplificada da base de cálculo do imposto de renda (IRPJ); e, da contribuição social sobre o lucro líquido (CSLL) das pessoas jurídicas que não são sujeitas à apuração do lucro real.

\subsubsection{Base de Cálculo do Imposto de Renda}

O limite da receita bruta para poder optar pelo lucro presumido é de até $\mathrm{R} \$ 48$ milhões da receita bruta total, no ano-calendário anterior, considerar-se-á nesta análise que as microempresas, consistem no faturamento anual de até $\mathrm{R} \$ 360.000,00$, para a pequena e média empresa um faturamento anual médio entre $\mathrm{R} \$ 360.000,01$ a $\mathrm{R} \$ 3.600 .000,00$, acima deste último valor enquadrarse-á no regime de Lucro Presumido para um faturamento de até $\mathrm{R} \$ 48.000 .000,00$.

As empresas acima deste valor devem optar pelo Lucro Real, nas seguintes condições: i) Receita superior no ano-calendário anterior, superior a $\mathrm{R} \$ 48.000 .000,00$ (quarenta e oito milhões), ou proporcional ao número de meses do período, quando inferior a 12 meses; ii) Cujas atividades sejam de instituições financeiras; iii) Obteve lucros, rendimentos ou ganhos de capital do exterior; iv) Àquelas que usufruam benefícios fiscais, redução, ou isenção autorizadas pela legislação tributária; v) Tenham efetuado pagamento mensal pelo regime de estimativa, no decorrer do ano-calendário, mediante balanço, ou balancete de suspensão, ou redução de imposto; vi) Cuja atividade seja de factoring, ou atividades comparadas.

Para analisar se esse regime é a melhor opção para a empresa, deve-se observar o regime tributário. É importante atentar ao fato de que as empresas tributadas pelo lucro presumido, não podem aproveitar os créditos do PIS e COFINS no sistema cumulativo, apesar de pagarem o PIS e COFINS em alíquotas mais baixas. Conforme a tabela 1.

Tabela 1- Percentuais de Presunção do Lucro Presumido: 


\begin{tabular}{lc}
\hline Atividades & Percentuais (\%) \\
\hline Atividades em geral (RIR/1999, art. 518) & 8,0 \\
Revenda de combustíveis & 1,6 \\
Serviços de transporte (exceto o de carga) & 16,0 \\
Serviços de transporte de cargas & 8,0 \\
Serviços em geral (exceto serviços hospitalares) & 32,0 \\
Serviços hospitalares & 8,0 \\
Intermediação de negócios & 32,0 \\
Administração, locação ou cessão de bens e direitos de qualquer natureza inclusive (imóveis) & 32,0 \\
\hline Fonte: Adaptado da Receita Federal (2016).
\end{tabular}

Fonte: Adaptado da Receita Federal (2016).

\subsubsection{Base de Cálculo Para PIS e COFINS}

A empresa que optar por este regime deverá recolher o PIS (Programa de Integração Social), na alíquota de $0,65 \%$ sobre a receita bruta e a COFINS (Contribuição para Financiamento da Seguridade Social), na alíquota de 3\% sobre a receita bruta mensalmente, observando o disposto na Lei $\mathrm{n}^{\circ}$ 9.715, de 1998, art. $8^{\circ}$. Conforme o exemplo detalhado no quadro 15 :

Quadro 15- Alíquota do PIS e COFINS:

\begin{tabular}{|l|c|c|c|}
\hline Imposto & Comércio e Indústria & Receitas mensais & Valor do Imposto \\
\hline PIS & $0,65 \%$ & $\mathrm{R} \$ 100.000,00^{*}$ & $\mathrm{R} \$ 650,00$ \\
\hline COFINS & $3,00 \%$ & $\mathrm{R} \$ 100.000,00^{*}$ & $\mathrm{R} \$ 3.000,00$ \\
\hline Totais & & & $\mathbf{R} \$ \mathbf{3 . 6 5 0 , 0 0}$ \\
\hline
\end{tabular}

Fonte: Dados organizados pelo(s) autor(es) (*valores de exemplificação).

\subsubsection{Base de Cálculo da Contribuição Social Sobre o Lucro Líquido (CSLL)}

Para tanto, as pessoas jurídicas que optam pelo regime de Lucro Presumido, deverá somar os seguintes valores conforme o quadro abaixo:

Quadro 16- Percentual para base de cálculo da CSLL:

\begin{tabular}{|c|l|}
\hline Percentual & Adição dos valores \\
\hline $12 \%$ & $\begin{array}{l}\text { Do total da receita bruta, das atividades comerciais, industriais, serviços hospitalares e de } \\
\text { transportes; }\end{array}$ \\
\hline $32 \%$ & $\begin{array}{l}\text { a) Para prestação de serviço em geral, exceto os serviços hospitalares e de transportes; } \\
\text { b) Intermediação de negócios; } \\
\text { c) Administração, locação ou cessão de bens imóveis, móveis e direitos de qualquer natureza; } \\
\text { d) Factoring, compra de direitos creditórios de vendas mercantis ou de prestação de serviços. }\end{array}$ \\
\hline
\end{tabular}

Fonte: Adaptado da Receita Federal (2016).

No exemplo a seguir (quadro 17) considerar-se-á uma empresa comercial, que apresenta um faturamento mensal de R \$100.000,00 pelo Lucro Presumido. Inicialmente tomamos como exemplo a apuração para o primeiro trimestre de 2015.

Quadro 17- Apuração de IRPJ e CSLL do Lucro Presumido-em comércio:

\begin{tabular}{|l|r|r|r|r|r|}
\hline MESES & RECEITA & B.C IRPJ 8\% & IRPJ 15\% & B.C. CSLL 12\% & CSLL 9\% \\
\hline JAN/2015 & $\mathrm{R} \$ 100.000,00 *$ & $\mathrm{R} \$ 8.000,00$ & $\mathrm{R} \$ 1.200,00$ & $\mathrm{R} \$ 12.000,00$ & $\mathrm{R} \$ 1.080,00$ \\
\hline FEV/2015 & $\mathrm{R} \$ 100.000,00 *$ & $\mathrm{R} \$ 8.000,00$ & $\mathrm{R} \$ 1200,00$ & $\mathrm{R} \$ 12.000,00$ & $\mathrm{R} \$ 1.080,00$ \\
\hline MAR/2015 & $\mathrm{R} \$ 100.000,00 *$ & $\mathrm{R} \$ 8.000,00$ & $\mathrm{R} \$ 1.200,00$ & $\mathrm{R} \$ 12.000,00$ & $\mathrm{R} \$ 1,080,00$ \\
\hline TOTAL & $\mathrm{R} \$ 300.000,00$ & $\mathrm{R} \$ 24.00,00$ & $\mathrm{R} \$ \mathbf{3 . 6 0 0 , 0 0}$ & $\mathrm{R} \$ 36.000,00$ & $\mathrm{R} \$ 3.240,00$ \\
\hline
\end{tabular}

Fonte: Dados organizados pelo(s) autor(es) (*valores de exemplificação). 
A ilustração no quadro 18 , considerou o pagamento mensal dos tributos federais (IRPJ e CSLL), portanto a Lei $\mathrm{n}^{\circ} 9430$, de 1996 , art. $26, \S 2^{\circ}$, ressalta que: o imposto de renda será apurado trimestralmente, por períodos encerrados em 31 de março, 30 de junho, 30 de setembro e 31 de dezembro de cada ano-calendário.

Quadro 18- Valor do imposto a recolher mensal - Lucro Presumido (Mensal)*:

\begin{tabular}{|c|c|c|c|c|}
\hline DESCRIÇÃO & IRPJ TRIMESTRAL & IRPJ MENSAL* & CSLL TRIMESTRAL & CSLL MENSAL* \\
\hline Valor total & $\mathbf{R} \$ \mathbf{3 . 6 0 0 , 0 0 / 3}$ & $\mathrm{R} \$ 1.200,00^{*}$ & $\mathrm{R} \mathbf{3 . 2 4 0 , 0 0 / 3}$ & $\mathrm{R} \$ 1.080,00^{*}$ \\
\hline Parcela & & $1^{*}$ & & $1^{*}$ \\
\hline $\begin{array}{c}\text { Valor a recolher } \\
\text { mensal* }\end{array}$ & & $\mathbf{R} \mathbf{1 . 2 0 0 , 0 0}$ & & $\mathbf{R} \mathbf{1 . 0 8 0 , 0 0}$ \\
\hline
\end{tabular}

Fonte: Dados organizados pelo(s) autor(es) (*valores de exemplificação).

\subsubsection{Adicional de Imposto de Renda de 10\% Para Empresas do Lucro Presumido e Contribuição Social sobre o Lucro Líquido (CSLL)}

Para FABRETTI (2008), após apurada a base de cálculo, aplica-se a alíquota de 15\% do IR (Imposto de Renda), mais o adicional de $10 \%$ (dez por cento) quando necessário, e alíquota de $9 \%$ (nove por cento) para a CSLL (Contribuição Social sobre o Lucro Líquido), mostrada no quadro abaixo.

Quadro 19- Demonstração do Resultado na empresa optante do Lucro Presumido:

\begin{tabular}{|c|c|c|}
\hline DISCRIMINAÇÃO & $(-)$ & $(+)$ \\
\hline Receita de Vendas & & $\mathbf{R} \$ 100.000,00 *$ \\
\hline (-) Impostos Sobre vendas & & $(\mathbf{R} \$ 15.650,00)$ \\
\hline ICMS sobre faturamento $-12 \%$ & $\mathrm{R} \$ 12.000,00$ & \\
\hline PIS sobre faturamento $-0,65 \%$ & $\mathrm{R} \$ 650,00$ & \\
\hline COFINS sobre faturamento $-3,00 \%$ & $\mathrm{R} \$ 3.000,00$ & \\
\hline (=) Receita Líquida & & R\$ 84.350,00 \\
\hline (-) Custos das mercadorias & & $(\mathbf{R} \$ 27.000,00)$ \\
\hline Compras de mercadorias & $\mathrm{R} \$ 27.000,00^{*}$ & \\
\hline ICMS sobre compra $12 \% *$ & & $\mathrm{R} \$ 3.240,00$ \\
\hline (=) Lucro Bruto & & $\mathrm{R} \$ 60.590,00$ \\
\hline (-) Despesas Operacionais & & $(\mathrm{R} \$ \mathbf{8 . 2 8 0 , 0 0})$ \\
\hline Despesas Administrativas & $\mathrm{R} \$ 3000,00^{*}$ & \\
\hline Despesas Financeiras & $\mathrm{R} \$ 3.000,00^{*}$ & \\
\hline IRPJ & $\mathrm{R} \$ 1.200,00^{*}$ & \\
\hline CSLL & $\mathrm{R} \$ 1.080,00^{*}$ & \\
\hline (=) Lucro líquido do exercício & & $\mathrm{R} \$ \mathbf{5 2 . 3 1 0 , 0 0}$ \\
\hline
\end{tabular}

Fonte: Dados organizados pelo(s) autor(es) (*valores de exemplificação).

-Não foi contabilizado o cálculo do INSS sobre a folha de pagamento.

-Não foi considerada a folha de pagamento dos empregados.

Quadro 20-Resumo de apuração dos impostos na opção do Lucro Presumido:

\begin{tabular}{|l|c|c|c|c|c|}
\hline Imposto & IRPJ & CSLL & PIS & COFINS & ICMS \\
\hline MENSAL* & $\mathbf{R} \$ 1.200,00 *$ & $\mathbf{R} \$ 1.080,00$ & $\mathbf{R} \mathbf{6 5 0 , 0 0}$ & $\mathbf{R} \$ \mathbf{3 . 0 0 0 , 0 0}$ & $\mathbf{R} \$ \mathbf{8 . 7 6 0 , 0 0}$ \\
\hline
\end{tabular}

Fonte: Dados organizados pelo(s) autor(es) (*valores de exemplificação).

No quadro acima, temos a venda de $\mathrm{R} \$ 100.000,00$ e a compra de $\mathrm{R} \$ 27.000,00$, encontra-se o PIS sobre o faturamento de $(650,00)$, COFINS sobre o faturamento de $(3.000,00)$, ICMS sobre venda no valor de $(12.000,00-3.240,00=\mathbf{8 . 7 6 0 , 0 0})$, IRPJ no valor de $\mathbf{1 . 2 0 0 , 0 0}$ e CSLL no valor de $\mathbf{1 . 0 8 0 , 0 0}$, totalizando $\mathrm{R} \$ \mathbf{1 4 . 6 9 0 , 0 0}$ em impostos. 


\subsubsection{O Lucro Real}

O Lucro Real, conforme quadro abaixo é o lucro líquido do período, considerando a legislação comercial e societária, ajustadas por meio de adições, exclusões, ou compensações prescritas pela legislação do Imposto de Renda (SILVA, 2006).Os impostos Federais optantes pelo Lucro Real são o PIS, a COFINS, o IRPJ e a CSLL, sendo o PIS e a COFINS apurados mensalmente sobre o faturamento; e, o IRPJ, a CSLL são calculados anualmente, ou trimestralmente tendo como base o lucro líquido contábil, ajustado pelas adições, exclusões e compensações autorizadas pelo Regulamento do Imposto de Renda.

Quadro 21-Demonstrativo do resultado na empresa do Lucro Real-em Comércio:

\begin{tabular}{|c|c|c|}
\hline DISCRIMINAÇÃO: & $(-)$ & $(+)$ \\
\hline Receita de Vendas & & $\mathbf{R} \$ 100.000,00 *$ \\
\hline (-) Impostos Sobre vendas & & $(\mathbf{R} \$ 21.250,00)$ \\
\hline ICMS sobre faturamento $-12 \%$ & $\mathrm{R} \$ 12.000,00$ & \\
\hline PIS sobre faturamento $-1,65 \%$ & $\mathrm{R} \$ 1.650,00$ & \\
\hline COFINS sobre faturamento $-7,60 \%$ & $\mathrm{R} \$ 7.600,00$ & \\
\hline (=) Receita Líquida & & $\mathbf{R} \$ \mathbf{7 8 . 7 5 0 , 0 0}$ \\
\hline (-) Custos das mercadorias & & $\mathrm{R} \$ 21.263,00$ \\
\hline Compras de mercadorias & $\mathrm{R} \$ 27.000,00^{*}$ & \\
\hline ICMS sobre compras $-12 \%$ & & $\mathrm{R} \$ 3.240,00$ \\
\hline PIS sobre compras $-1,65 \%$ & & $\mathrm{R} \$ 445,00$ \\
\hline COFINS sobre compras $-7,60 \%$ & & $\mathrm{R} \$ 2.052,00$ \\
\hline (=) Lucro Bruto & & R\$ 57.487,00 \\
\hline (-) Despesas Operacionais & & $(\mathrm{R} \$ \mathbf{6 . 0 0 0 , 0 0})$ \\
\hline Despesas Administrativas & $\mathrm{R} \$ 3.000,00^{*}$ & \\
\hline Despesas Financeiras & $\mathrm{R} \$ 3.000,00^{*}$ & \\
\hline (=) Lucro antes do IRPJ & & $\mathrm{R} \$ \mathbf{5 1 . 4 8 7 , 0 0}$ \\
\hline (-) Imposto sobre o lucro & & $(\mathrm{R} \$ 12.356,88)$ \\
\hline IRPJ $-15 \%$ & $\mathrm{R} \$ 7.723,05$ & \\
\hline CSLL $-9 \%$ & $\mathrm{R} \$ 4.633,83$ & \\
\hline (=) Lucro líquido do exercício & & $\mathbf{R} \$ 39.130,12$ \\
\hline
\end{tabular}

Fonte: Dados organizados pelo(s) autor(es) (*valores de exemplificação).

-Não foi contabilizado o INSS e a folha de pagamento.

A apuração do lucro real envolve todas as demonstrações contábeis como: Balanço Patrimonial, Demonstração de Resultado do Exercício, Demonstrações das mutações do patrimônio líquido, balancetes e livros, o Livro de Apuração do Lucro Real (LALUR) de entrada e saída; e, o Livro Registro de Inventário, no quadro 22.

Quadro 22-Resumo de apuração dos impostos na opção do Lucro Real-em Comércio:

\begin{tabular}{|l|c|c|c|c|c|}
\hline IMPOSTO & IRPJ & CSLL & PIS & COFINS & ICMS \\
\hline VALOR & R\$ 7.723,05 & $\mathbf{R} \mathbf{4 . 6 3 3 , 8 3}$ & $\mathbf{R} \mathbf{1 . 2 0 5 , 0 0}$ & $\mathbf{R} \$ \mathbf{5 . 5 4 8 , 0 0}$ & $\mathbf{R} \mathbf{8 . 7 6 0 , 0 0}$ \\
\hline
\end{tabular}

Fonte: Dados organizados pelo(s) autor(es) (*valores de exemplificação).

Os impostos federais, como IRPJ e CSLL são pagos trimestralmente, no exemplo mencionado no quadro 23, considera-se mensalmente, apenas para ilustração, já o PIS, COFINS e ICMS são pagos mensalmente. A figura acima mostra a comparação entre os tributos. 
Quadro 23- Comparação de impostos entre Simples Nacional, Lucro Presumido e Lucro Real - em Comércio:

\begin{tabular}{|l|r|r|r|}
\hline Descrição & Simples Nacional & Lucro Presumido & Lucro Real \\
\hline Receita mensal & $\mathrm{R} \$ 100.000,00^{*}$ & $\mathrm{R} \$ 100.000,00^{*}$ & $\mathrm{R} \$ 100.000,00^{*}$ \\
\hline Base de Cálculo & $\mathrm{R} \$ 100.000,00^{*}$ & $\mathrm{R} \$ 8.000,00^{*}$ & $\mathrm{R} \$ 100.000,00^{*}$ \\
\hline PIS & $\mathrm{R} \$ 280,00$ & $\mathrm{R} \$ 650,00$ & $\mathrm{R} \$ 1.205,00$ \\
\hline COFINS & $\mathrm{R} \$ 1.160,00$ & $\mathrm{R} \$ 3.000,00$ & $\mathrm{R} \$ 5.548,00$ \\
\hline ICMS & $\mathrm{R} \$ 1.830,00$ & $\mathrm{R} \$ 8.760,00$ & $\mathrm{R} \$ 8.760,00$ \\
\hline IRPJ & $\mathrm{R} \$ 390,00$ & $\mathrm{R} \$ 1.200,00$ & $\mathrm{R} \$ 7.723,05$ \\
\hline CSLL & $\mathrm{R} \$ 390,00$ & $\mathrm{R} \$ 1.080,00$ & $\mathrm{R} \$ 4.633,83$ \\
\hline INSS/CPP & $\mathrm{R} \$ 3.300,00$ & & \\
\hline Total & $\mathbf{R} \$ \mathbf{7 . 3 5 0 , 0 0}$ & $\mathbf{R} \$ \mathbf{1 4 . 6 9 0 , 0 0}$ & $\mathbf{R} \$ \mathbf{2 7 . 8 6 9 , 8 8}$ \\
\hline
\end{tabular}

Fonte: Dados organizados pelo(s) autor(es) (*valores de exemplificação).

\section{Conclusão}

O esclarecimento da "substituição tributária", não está em conformidade com o que prescreve a Lei Complementar 123/2006, além disso, permite que cada Estado alimentado pela guerra físcal, quebre por meio de Lei, o tratamento diferenciado atribuído para as MPEs, onde normas gerais se encontram reguladas em lei complementar. Diante disso, os governantes não oferecem diferenciação na arrecadação da substituição tributária, contrariando o art. 179 da Constituição Federal. Outros princípios ainda são violados como: da isonomia, capacidade contributiva, princípio da reserva legal que atribuiu à lei complementar de estabelecer regime de tributação das pequenas empresas, o princípio da pequena empresa na ordem econômica.

Assim, diante do exposto, conclui-se em seu conjunto, que a prática tributária, precisa ser muito bem estudada e planejada pelo contabilista, caso contrário, ela tem amplas chances de desfavorecer ao pequeno empresário, ou seja, para as empresas optantes ao Simples Nacional. O que pode tornar a opção deste regime inconveniente para as MPEs que comercializam, ou produzam com incidência de substituição tributária, a própria lei contradiz outra lei tornando-a inconstitucional a versão no que diz respeito à Lei 123 de dezembro de 2006. Portanto, a opção pelo Simples nacional, pode ser vantajosa, pois a incidência dos tributos é mais baixa, quando comparadas com os regimes de tributação, Lucro Presumido e Lucro Real. Para tanto, depende dos produtos produzidos, ou comercializados pela empresa possa fazer jus ao benefício; e, ainda se faz necessário um minucioso planejamento tributário, para analisar qual é a melhor e eficaz alternativa para a empresa adotar seu regime de tributação; e, nesse contexto elaborar estratégias que lhe permitam auferir ganhos e ampliar suas condições competitivas no mercado.

\section{Referências bibliográficas}

ASSEF, Roberto. Guia prático de formação de preços: aspectos mercadológicos, tributários e financeiros para pequenas e médias empresas. 2.ed. rev. e at. Rio de Janeiro, 2003.

COGAN, Samuel. Custos e Preços - Formação e Análise. 1ª ed. Pioneira: São Paulo, 2002.

CONSTITUIÇÃO FEDERAL 1988. Artigo 179. <http://www.planalto.gov.br/ccivil_03/constituicao /ConstituicaoCompilado.htm> Acessado em: 30 de janeiro de 2016.

FABRETTI, Láudio Camargo. Contabilidade Tributária e Societária para Advogados. $2^{\circ}$ Edição. São Paulo: Atlas, 2008

Lei ${ }^{\circ}$ 9.715, de 25 e novembro de 1998. Contribuições para os Programas de Integração 15 providências. Disponível em:<http://www.planalto.gov.br/ccivil_03/LEIS/L9715.htm>. Acessado em: 04 de fevereiro de 2016.

MELCHOR, Paulo. Substituição Tributária das Empresas no Simples Nacional - ICMS e ISS. 2008. 
SEFA. Percentual de Redução do ICMS no Paraná, disponível em: http://www.sefanet.pr.gov.br/dados/sefadocumentos/2201203822.pdf. Acesso em: 10 de fevereiro de 2016.

REZENDE, Amaury José; PEREIRA, Carlos Alberto; ALENCAR, Roberta Carvalho de. Contabilidade das empresas. São Paulo: Atlas, 2010.

SANTOS, Antônio Dorvalino dos. Projeto de Educação Continuada: Apuração do IRPJ e CSLL com base no Lucro Real e Presumido. CRC/SC, Florianópolis, maio de 2008.

SILVA, J. Miguel; RODRIGUES, Agostinho Inácio. LALUR Guia Prático de Escrituração do Livro de Apuração do Lucro Real, 2006. 4. ed. São Paulo, Cenofisco, 2006.

SIMPLES.Tabela do simples nacional. <http://www.normaslegais.com.br>Acesso em: 22 de fevereiro de 2016.

SOUZA, Rodrigo Leme Dias de; FRANCO, Aline Grabrieli Santos; SOUZA, Adriano Augusto de; SILVA, Janaina Simone da. Contabilidade tributária simples nacional: teórica: simplificação. In: Congresso Brasileiro de Contabilidade, Gramado - RS, 2008.

WANKE, Peter F; MAGALHÃES, Andréa. Lei no 123 de 2006. Estatuto Nacional da Microempresa e da Empresa de Pequeno Porte. 